\title{
VERIFICAÇÃO DA QUALIDADE MICROBIOLÓGICA DE MEDICAMENTOS CONTENDO PARACETAMOL ENCONTRADOS EMALGUMAS RESIDÊNCIAS DE AMÉRICO BRASILIENSE/SP
}

TÓTOLI, Eliane Gandolpho; STAIN, Samaria Nascimento. Farmacêuticas graduadas pelo Centro

Universitário de Araraquara - Uniara.

SALGADO, Hérida Regina Nunes. Docente da Faculdade de Ciências Farmacêuticas da Universidade

Estadual Paulista - Unesp.

MORENO, Andréia de Haro*. Docente do Centro Universitário de Araraquara - Uniara.

*E-mail: ahmoreno@uniara.com.br.

\section{RESUMO}

Sabe-se que elevadas cargas microbianas podem comprometer a estabilidade de medicamentos, prejudicando sua eficácia terapêutica. O presente trabalho buscou demonstrar que a contaminação microbiana pode estar diretamente envolvida com a manipulação inadequada dos medicamentos mantidos nas residências, tornando possível traçar estratégias para reduzir possíveis riscos à terapia medicamentosa, por meio de orientação e informação adequadas. O objetivo deste trabalho foi avaliar a qualidade microbiológica de medicamentos em gotas contendo paracetamol encontrados em residências de Américo Brasiliense/SP, através do método de análise para produtos não-estéreis descrito na Farmacopeia Brasileira (1988). As amostras de medicamento em uso (30 amostras) foram obtidas diretamente dos moradores entrevistados, que receberam frascos novos do mesmo produto. Foram realizadas a contagem de micro-organismos viáveis (bactérias e fungos) e a pesquisa e identificação de patógenos nas amostras coletadas. Apesar de $90 \%$ das amostras apresentarem contaminação, os resultados indicaram ausência de micro-organismos patogênicos, bem como contagem total de microorganismos viáveis abaixo do valor máximo permitido para produtos não-estéreis $\left(10^{4} \mathrm{UFC} / \mathrm{g}\right.$ ou mL) nas amostras analisadas. Também foi verificado que os moradores entrevistados armazenavam os medicamentos em locais apropriados, de acordo com as orientações recebidas no momento da aquisição dos mesmos nas farmácias e drogarias, ressaltando a importância da informação para o correto uso e conservação de medicamentos.

Palavras-chave: Controle de qualidade; Paracetamol; Análise microbiológica; Conservação de medicamentos.

\section{Abstract}

It is known that a high microbial count can compromise the stability of medicines, thus reducing their therapeutic efficacy. This work tried to demonstrate that the microbial contamination can be directly related to the inadequate handling of the medicines stored in homes, making it possible to draw strategies to reduce the possible risks of medical therapy offering correct information and advising. The objective of this work was to evaluate the quality of the medicines containing paracetamol found in the residences of Américo Brasiliense-SP, using the microbial analysis of non-sterile method described in the Brazilian Pharmacopoeia (1988). The medicine samples (30 samples) were obtained directly from the interviewed local residents, who had received new medicine bottles of the same product. An analysis of viable microorganisms (bacteria and fungus) was carried out to identify pathogens found in the collected samples. Although $90 \%$ of the analyzed samples have shown some microbial contamination, the results indicated the absence of pathogenic microorganisms, and the total count of viable microorganisms was below the maximum value for non-sterile $\left(10^{4} \mathrm{UFC} / \mathrm{g}\right.$ or $\left.\mathrm{mL}\right)$. It was also verified that the local residents stored the medicines in appropriate places, according to the orientations received when they bought the medicines in pharmacies and drugstores, showing the importance of information for the correct use and conservation of pharmaceuticals. 
KeYwOrds: Quality control; Paracetamol; Microbiological analysis; Drug conservation.

\section{INTRODUÇão}

A prática de armazenar medicamentos nas residências, no Brasil, é um aspecto cultural. Porém, essa atitude pode acarretar vários problemas, como, por exemplo, a contaminação microbiana, que pode ser decorrente de armazenamento e/ou manipulação inadequados por parte dos pacientes, entre outros fatores (SERAFIM et al., 2007). Além disso, esse hábito pode contribuir para o uso irracional dos mesmos.

Nos últimos tempos, muitos países vêm se preocupando com o uso irracional de medicamentos, principalmente devido aos efeitos prejudiciais à saúde que tal prática pode ocasionar. Tendo em vista esse fato, Hepler e Strand (1999) deram o impulso inicial para o desenvolvimento de uma nova prática, a atenção farmacêutica, a qual se difundiu mundialmente.

Atenção farmacêutica é compreendida como um modelo de prática profissional desenvolvida no contexto da assistência farmacêutica. Nesse modelo, o paciente é o principal beneficiário das ações do farmacêutico. Segundo a RDC n. ${ }^{\circ}$ 357, de 20 de abril de 2001 (BRASIL, 2001), atenção é o compêndio das atitudes, dos comportamentos, dos compromissos, das inquietudes, dos valores éticos, das funções, dos conhecimentos, das responsabilidades e das habilidades do farmacêutico na prestação da farmacoterapia, com objetivo de alcançar resultados terapêuticos definidos na saúde e na qualidade de vida do paciente. Portanto, possui como finalidade aumentar a efetividade do tratamento medicamentoso, detectando problemas relacionados a medicamentos (OLIVEIRA etal., 2005).

Quando transferimos esses conceitos para a prática cotidiana, podemos dizer que Atenção Farmacêutica é um modelo de prática profissional que consiste na promoção da farmacoterapia responsável, com o propósito de alcançar resultados concretos em resposta à terapêutica prescrita, que melhorem a qualidade de vida do paciente (LYRA JÚNIOR et al., 2005). Nessa prática, há o envolvimento direto do paciente com o farmacêutico, que deve responsabilizar- se junto com o mesmo para que o medicamento prescrito seja seguro e eficaz, na posologia correta, e resulte no efeito terapêutico desejado, além de atentar para que, ao longo do tratamento, as reações adversas aos medicamentos sejam as mínimas possíveis e, quando surgirem, possam ser resolvidas imediatamente (OLIVEIRA et al., 2004; FREITAS et al., 2006; FERREIRA, 2007; PEREIRA; FREITAS, 2008; SOUZA; BERTONCIN, 2008; ZAVALETABUSTOS et al., 2008; PRETTI et al., 2009).

A contaminação microbiana pode causar infecções em pessoas cujo sistema imunológico se encontra enfraquecido e, por tal motivo, as torna mais suscetíveis a infecções. Os medicamentos são frequentemente administrados em situações como essa. Outro fator de grande relevância é a capacidade que alguns microorganismos têm de degradar os produtos, diminuindo sua eficácia. Esses motivos, entre outros, mostram a importância do controle de qualidade de medicamentos. Essa importância se torna ainda maior quando pensamos que nossa própria vida, muitas vezes, depende dos mesmos (PINTO et al., 2003).

Dessa forma, o armazenamento do medicamento em condições adequadas é muito importante, pois minimiza a ocorrência de alterações no produto. Assim, é importante que o número de micro-organismos encontrados seja o menor possível, uma vez que, se as condições ambientais forem adequadas, eles podem se multiplicar e, posteriormente, causar alterações nas propriedades organolépticas, perda de estabilidade e a atividade do princípio ativo do medicamento (DE LA ROSA et al., 1995).

Vale lembrar que o armazenamento inadequado de medicamentos também pode acelerar reações químicas de deterioração de fármacos, diminuindo seu prazo de validade, sendo essas reações classificadas em: incompatibilidade, oxidação, redução, hidrólise, descarboxilação, racemização e epimerização, desidratação, reações fotoquímicas, entre outros (FERREIRA, 2002; GENNARO, 2004).

O trabalho em questão representa a análise microbiológica de medicamentos contendo paracetamol (solução oral), que foram recolhidos aleatoriamente de 
residências de Américo Brasiliense/SP. Trata-se de um produto não-estéril, ou seja, admite certa carga microbiana, porém limitada e restrita a determinadas cepas microbianas, considerando as características de sua utilização (PINTO et al., 2003). Além disso, é um dos fármacos mais importantes utilizados para $\mathrm{o}$ tratamento de dor e febre, quando não há necessidade de obter-se um efeito anti-inflamatório (GENNARO, 2004; KATZUNG, 1998; CHANDRASEKHARAN et al., 2002; ANDREI et al., 2003).

O objetivo imediato da análise microbiológica de produtos não-estéreis, que foi realizada de acordo com a Farmacopeia Brasileira (1988), é comprovar a ausência de cepas patogênicas, como, por exemplo, Staphylococcus aureus, Salmonella sp, Escherichia coli e Pseudomonas aeruginosa, além de determinar o número de micro-organismos viáveis, em função do tipo da utilização do produto (PINTO et al., 2003).

Sabe-se que elevadas cargas microbianas podem comprometer a estabilidade de medicamentos, podendo prejudicar sua eficácia terapêutica. Dessa forma, é importante demonstrar que a contaminação microbiana pode estar diretamente envolvida com a manipulação inadequada dos medicamentos mantidos nas residências. Assim, será possível traçar estratégias para reduzir possíveis riscos à terapia medicamentosa, através da orientação e informação aos usuários de medicamentos (SERAFIM et al., 2007).

\section{Metodologia}

\section{Obtenção das amostras}

As amostras analisadas de medicamentos em gotas contendo paracetamol foram obtidas aleatoriamente (mediante concordância por parte dos moradores entrevistados) em residências da cidade de Américo Brasiliense/SP, após a aplicação de um questionário para 30 moradores que utilizavam o medicamento no primeiro semestre de 2009 (Quadro 1). No momento da entrevista, foi entregue um folheto educativo com orientações sobre o descarte e armazenamento de medicamentos (Quadro 2). Tanto o questionário quanto o folheto educativo foram baseados em modelos aplicados por Serafim e colaboradores
(2007). Posteriormente, as informações obtidas dos questionários foram analisadas e relacionadas com os resultados obtidos na análise microbiológica das amostras. Cabe aqui lembrar que não houve risco nenhum para os voluntários, pois eles apenas forneceram as amostras de medicamentos em gotas contendo paracetamol e receberam um frasco novo do mesmo medicamento em substituição ao fornecido, além de preencher o questionário, de acordo com o protocolo número 917/09 aprovado pelo Comitê de Ética em Pesquisa da Uniara.

\section{Preparo das amostras}

Foi transferido $1 \mathrm{~mL}$ de cada amostra para tubo de ensaio contendo $9 \mathrm{~mL}$ de solução tampão fosfato $\mathrm{pH}$ 7,2 adicionado de $1 \%$ de Polissorbato 80 , para inativar o conservante. Partindo dessa diluição, alíquotas foram transferidas para determinados meios de cultura, com a finalidade de efetuar a contagem do número total de micro-organismos na amostra e também a de pesquisar os micro-organismos indesejáveis (Pseudomonas aeruginosa, Staphylococcus aureus, Escherichia coli e Salmonella sp) (FARMACOPEIA BRASILEIRA, 1988; PINTO et al., 2003; SERAFIM et al., 2007).

\section{Reagentes e soluções}

Solução de $\mathrm{HCl}$ 0,02 N: preparada a partir de uma solução a $1 \mathrm{~N}$ (85 mL de ácido clorídrico p.a. Merck em balão de 1000 mL e completado o volume comágua deionizada). Foi utilizada uma alíquota de $20,00 \mathrm{~mL}$ da solução a $1 \mathrm{~N}$, transferida para balão volumétrico de 1000 mLe completado o volume com água deionizada.

\section{Contagem do número total de micro- organismos}

Nessa etapa, foram utilizados os meios ágar tioglicolato e ágar Sabouraud. Alíquotas de $1 \mathrm{~mL}$ da diluição foram transferidas para placas de Petri, com a seguida adição de $20 \mathrm{~mL}$ de meio liquefeito a $47^{\circ} \mathrm{C} \mathrm{com}$ homogeneização em $\mathrm{S}$ ou 8. Foramutilizadas três placas com o ágar tioglicolato e três com o ágar Sabouraud, por amostra (diluída em tampão fosfato pH 7,2). 
Após a solidificação dos meios de cultura, as placas contendo o ágar tioglicolato foram incubadas a 30$35^{\circ} \mathrm{C}$ durante 24 horas, e as placas contendo o ágar Sabouraud, a $20-25^{\circ} \mathrm{C}$ durante 7 dias. Após esse período, foi realizada a contagem do número de colônias (de bactérias, no ágar tioglicolato, e de fungos, no ágar Sabouraud), com o auxílio de contador automático de colônias, calculando o número de Unidades Formadoras de Colônia (UFC) (FARMACOPEIABRASILEIRA, 1988; PINTO et al., 2003; SERAFIM et al., 2007).

\section{Pesquisa de Salmonella sp e Escherichia coli}

Foi transferido, assepticamente, $1 \mathrm{~mL}$ de cada amostra para $9 \mathrm{~mL}$ de caldo lactosado adicionado de $1 \%$ de Polissorbato 80, para pesquisa de Salmonella sp e $E$. coli. $\mathrm{O}$ caldo foi incubado a $35^{\circ} \mathrm{C}$ durante 24 a 48 horas. Após esse período, $1 \mathrm{~mL}$ do caldo lactosado foi transferido para dois tubos contendo caldo tetrationato e dois tubos contendo caldo selenito cistina, que foram incubados a $35^{\circ} \mathrm{C}$ durante 24 horas. Após esse período, a amostra foi semeada do caldo tetrationato para um tubo contendo ágar verde brilhante e duas placas de Petri contendo ágar XLD e ágar bismuto sulfito. O mesmo foi feito com a amostra inoculada no caldo selenito cistina, transferindo para os três meios, os quais foramincubados a $35^{\circ} \mathrm{C}$ durante 24 horas. $\mathrm{O}$ crescimento e as características das colônias foramobservados. As colônias suspeitas foram semeadas comalça reta em tubo contendo ágar TSI e incubadas a $35^{\circ} \mathrm{C}$ durante 24 horas. As características das colônias foram observadas.

Na pesquisa de E. coli, $1 \mathrm{~mL}$ do caldo lactosado foi transferido para placa contendo ágar MacConkey e incubado a $35^{\circ} \mathrm{C}$ durante 24 horas. As colônias suspeitas foram semeadas em ágar EMB e incubadas a $35^{\circ} \mathrm{C}$ durante 24 horas. As características das colônias foram observadas (FARMACOPEIA BRASILEIRA, 1988; PINTO et al., 2003; SERAFIM et al., 2007).

\section{Pesquisa de Staphylococcus aureus e Pseudomonas aeruginosa}

Foi transferido, assepticamente, $1 \mathrm{~mL}$ de cada amostra para $9 \mathrm{~mL}$ de caldo peptonado adicionado de Polissorbato 80, para pesquisa de Staphylococcus aureus e Pseudomonas aeruginosa, e incubados a $35^{\circ} \mathrm{C}$ por 24 a 48 horas. Após esse período, com auxílio de alça de platina, foi semeado em ágar Vogel-Johnson, para a pesquisa de $\mathrm{S}$. aureus, e ágar cetrimida, para a pesquisa de $\mathrm{P}$. aeruginosa, a $35^{\circ} \mathrm{C}$ durante 24 horas. As características das colônias foram observadas (FARMACOPEIA BRASILEIRA, 1988; PINTO et al., 2003; SERAFIM et al., 2007).

\section{Resultados e discussão}

Foram analisados 30 frascos de medicamentos contendo paracetamol, de variadas marcas comerciais, as quais foram identificadas como $\mathrm{A}(66,7 \%), \mathrm{B}(6,7 \%)$, $\mathrm{C}(3,3 \%), \mathrm{D}(10 \%), \mathrm{E}(6,7 \%)$ e F $(6,7 \%)$. É importante ressaltar que todos os medicamentos analisados estavam dentro do prazo de validade, e os conservantes utilizados nas formulações foram: metilparabeno e propilparabeno (A, C e F, ou seja, 76,7\%) e benzoato de sódio (B, D e E, ou seja, 23,3\%).

Por meio da análise microbiológica dos frascos, verificou-se que a maioria dos medicamentos $(90 \%)$ apresentou alguma contaminação por bactérias e/ou fungos, sendo isenta das bactérias patogênicas. Entretanto, o número de colônias nas placas não ultrapassou o limite permitido para produtos nãoestéreis, determinado pela Federação Internacional Farmacêutica - FIP, que é de $10^{4}$ UFC/mL (PINTO et al., 2003). É importante ressaltar que a amostra 14 se encontrava sem tampa, e assim mesmo se apresentou isenta de contaminação.

Apesar de Pinto et al. (2003) afirmarem que os parabenos, grupo mais popular de conservantes, podem apresentar falhas quando aplicados individualmente, o presente trabalho verificou o contrário, pois a maioria dos medicamentos analisados (76,7\%) utiliza metilparabeno e propilparabeno como sistema conservante e, mesmo assim, não apresentou contaminações acima do limite especificado. Além disso, não houve diferença significativa da contaminação desses medicamentos, que utilizam parabenos como conservantes, para os que utilizam 
benzoato de sódio. Dessa forma, verificou-se que a atividade conservante foi suficientemente rápida para garantir que qualquer contaminação ocasionada pelo consumidor fosse eliminada no período entre os usos. Também foi possível afirmar que o sistema conservante dos medicamentos analisados não foi degradado pelos microrganimos presentes, pois ainda foi capaz de manter a contaminação abaixo do limite permitido.

Sabe-se que a presença de sistema antimicrobiano efetivo é fundamental, principalmente em formas líquidas de base aquosa, como é o caso do paracetamol em gotas, para garantir a estabilidade e segurança de preparações farmacêuticas não-estéreis com relação à pureza microbiana.

Tratando-se do questionário aplicado (Quadros 1 e 2), observou-se que a faixa etária dos voluntários variou de 18 a 67 anos, sendo 63,3\% de sexo feminino e $36,7 \%$ de sexo masculino. Verificou-se que a maioria dos entrevistados (40\%) citou quatro pessoas morando em sua residência e utiliza o medicamento contendo paracetamol de marca comercial A, que representou $66,7 \%$ dos medicamentos recolhidos.

\section{Questionário}

Identificação

1.Idade: anos

2.Sexo: ( ) M ( ) F

3.Número de pessoas na casa: ( ) 0-12 anos ( ) 13-65 anos ( ) acima de 65 anos

Paracetamol

1.Possui paracetamol em casa? ( ) Sim （ ) Não

2.Qual o nome do medicamento?

3.Como armazena medicamentos em casa?

4.Como é o descarte?

5.Há quanto tempo guarda este medicamento em sua casa?

( ) 1 ano ou mais ( ) 6 meses ( ) 1 mês

6.Você lê a bula? ( ) Sim ( ) Não

7.Quem indicou o paracetamol?

( ) Farmacêutico ( ) Balconista ( ) Amigo ( ) Médico ( ) Dentista

8.Quando toma o paracetamol?

$\underline{\text { Geral }}$

1.Conhece a profissão farmacêutica? ( ) Sim ( ) Não

2.Conhece os medicamentos genéricos? ( ) Sim ( ) Não

3.Possui medicamentos vencidos em sua residência? ( ) Sim ( ) Não

4.Compra medicamentos com prescrição médica? ( ) Sim ( ) Não

Obs:

Quadro 1 - Questionário utilizado nas entrevistas realizadas nas residências. 


\section{ORIENTACÃO PARA O ARMAZENAMENTO E DESCARTE DE MEDICAMENTOS}

\section{DESCARTE}

\section{Medicament os vencidos}

Líquidos: devem ser dispensados em água corrente (pia, tanque ou vaso sanitário), sendo a embalagem descartada diretamente no lixo após lavagem, com exceção dos medicamentos especiais*, que devem ser encaminhados, preferencialmente, a alguma farmácia ou local responsável pela coleta.

Sólidos (comprimidos, cápsulas, drágeas): podem ser dissolvidos em água e dispensados em água corrente (pia, tanque ou vaso sanitário) ou enterrados, com exceção dos medicamentos especiais*, que devem ser encaminhados, preferencialmente, a alguma farmácia ou local responsável pela coleta.

\section{Medicamentos especiais*}

Controlados (tarja preta), antimicrobianos, hormônios, citostáticos, antineoplásicos, imunossupressores, digitálicos, imunomoduladores, antirretrovirais devem ser encaminhados para local responsável pela coleta (Vigilância Sanitária, Postos de Saúde, Prefeituras, etc.).

\section{ARMAZENAMENTO}

- Todos os medicamentos devem ser armazenados em locais protegidos da luz, da umidade, calor, radiação e do alcance das crianças. Não deixá-los em locais como pias, banheiros, armários próximos a janelas, a fogões ou a fornos de microondas.

- Lavar bem as mãos antes de qualquer manuseio com medicamentos.

- Não deixar frascos abertos ou desprotegidos a fim de evitar contaminação ou degradação.

- Nunca armazenar medicamentos juntamente com alimentos.

\section{ATENÇÃO !}

Não utilizar medicamentos com sinais de degradação ou deterioração, tais como: odor alterado, mudança de coloração e/ou consistência, formação de bolhas ou gases, ressec amento ou formação de sedimento ou precipitado.

Quadro 2 - Informações contidas no folheto educativo como orientação para o descarte de medicamentos. 
Quanto ao local de armazenamento, os entrevistados relataram caixas de sapato dentro e sobre o guardaroupa, gavetas, caixas de sapato dentro ou sobre o armário da cozinha, cômoda do quarto, caixa de primeiros-socorros na cozinha, sobre a estante, caixas de sapato em local fresco, e também foi relatado local seguro, longe de calor, umidade e alcance de crianças. Observou-se que a maioria utiliza caixas de sapato dentro do armário da cozinha para armazenar medicamentos (Figura 1).

\section{Local de armazenamento de medicamentos}

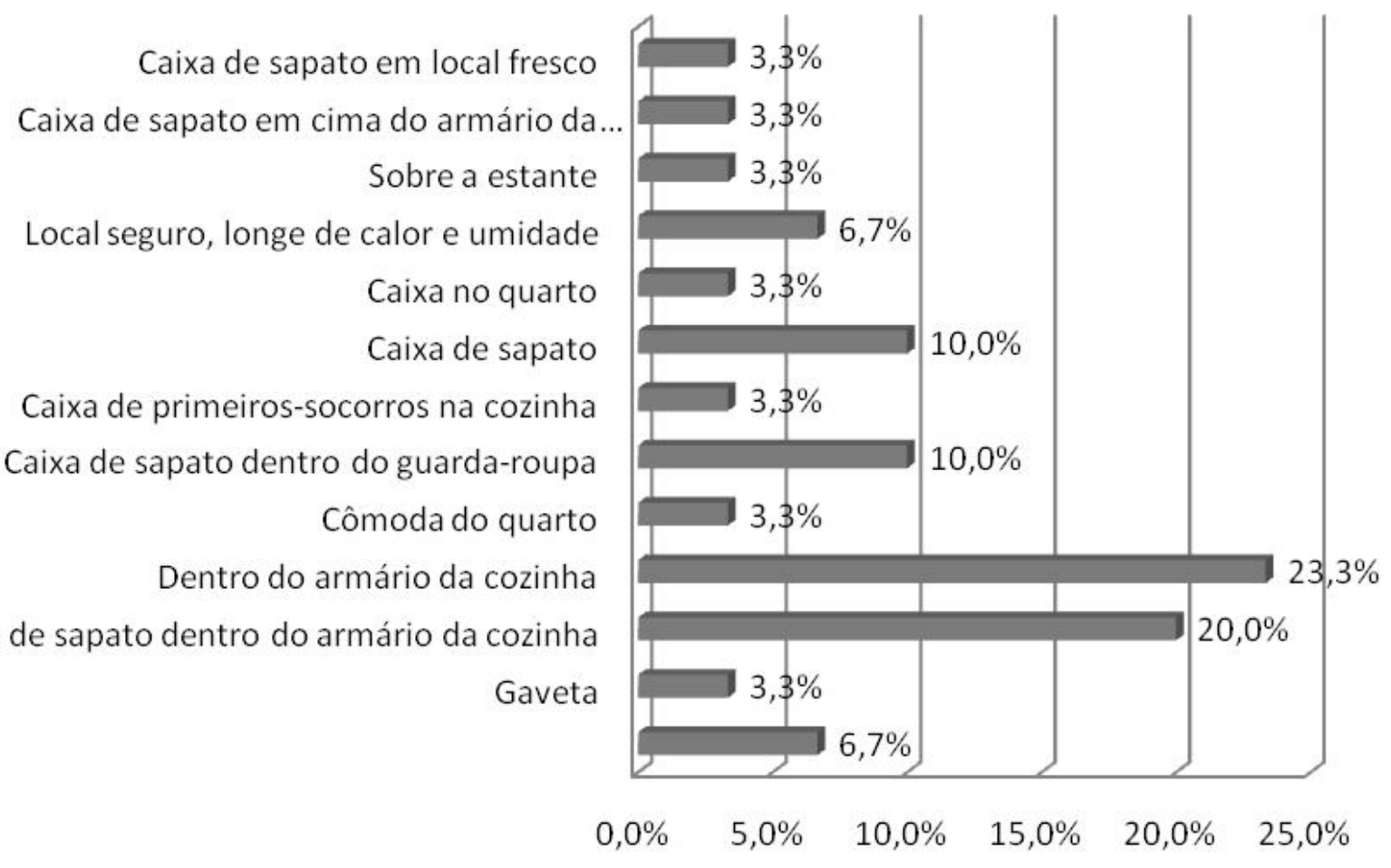

Figura 1 - Local de armazenamento de medicamentos relatados pelos entrevistados.

Nota-se que a maior porcentagem dos entrevistados citou a cozinha $(49,9 \%)$ como local de escolha para o armazenamento de medicamentos, provavelmente em decorrência da maior acessibilidade ao local, à presença de líquidos que podem ser ingeridos conjuntamente com o medicamento e de utensílios domésticos como colheres para medida de líquidos e suspensões (SCHENKEL et al., 2005). Na cozinha, o local preferido dos entrevistados foi o armário, embora este local não seja o mais apropriado, pois nunca se devem armazenar medicamentos juntamente comalimentos. De todos os entrevistados, apenas $10 \%$ ressaltaram a importância de armazenar os medicamentos em local fresco, longe de calor e umidade.

É importante ressaltar que medicamentos não devem ser armazenados em locais como pias, banheiros, armários próximos a janelas, fogões ou a fornos de microondas. Tambémé importante ressaltar a correta lavagem das mãos antes de qualquer manuseio com medicamentos, não deixar frascos abertos ou desprotegidos, a fim de evitar contaminação ou degradação, e nunca armazenar medicamentos juntamente com alimentos (SERAFIM et al., 2007). 
A prática de armazenar medicamentos nas residências pode acarretar vários problemas, como, por exemplo, a contaminação microbiana dos mesmos. Outro problema relacionado ao armazenamento de medicamentos está ligado ao acesso a esse local, devendo evitar que crianças e animais domésticos entrem em contato com a medicação, evitando acidentes como intoxicação e a contaminação dos medicamentos, fatores que podem trazer prejuízos graves à saúde e, em casos extremos, podem levar o indivíduo ao óbito (LIMA et al., 2008).

As principais reações de degradação de medicamentos são favorecidas como armazenamento inadequado. A oxidação, por exemplo, pode ser acelerada com a elevação da temperatura. Em relação à hidrólise, sabe-se que para cada $10^{\circ} \mathrm{C}$ de elevação na temperatura de armazenagem, a taxa de reação dobra ou triplica; além disso, o armazenamento em locais úmidos também aumenta a probabilidade de essa reação ocorrer. Já a descarboxilação é altamente dependente de $\mathrm{pH}$ e temperaturas elevadas. A racemização também é dependente da temperatura e da presença de luz. É importante ressaltar que as reações de fotólise representam um fator limitante na estabilidade de produtos farmacêuticos, podendo catalisar reações como oxidação e hidrólise. Por todos esses fatores, é importante que os medicamentos sejam armazenados em locais protegidos da luz, da umidade, calor, radiação (FERREIRA, 2002; GENNARO, 2004).

Prazo de validade é o tempo durante o qual o produto poderá ser usado, possuindo relação direta com as reações de degradação anteriormente citadas (FARMACOPEIA BRASILEIRA, 1988). Vale lembrar que o armazenamento desses medicamentos de forma inadequada pode antecipar seu prazo de validade. A grande maioria dos entrevistados $(93,3 \%)$ afirmou não possuir medicamentos vencidos em suas residências, porém, um dos frascos fornecidos estava sem tampa, o que se pode supor que encurtou seu prazo de validade, embora não tenha sido verificada contaminação microbiológica.

Em relação ao tempo de armazenamento dos medicamentos, 43,3\% dos entrevistados relatou guardá-los por seis meses. Foram relatadas formas de descarte, tais como: diretamente no lixo doméstico, lavar o vidro e descartá-lo no lixo, levar o medicamento a uma farmácia, diretamente no vaso sanitário, na pia e ainda foi relatado nunca sobrar medicamento (Figura 2). 


\section{Local de descarte de medicamentos}

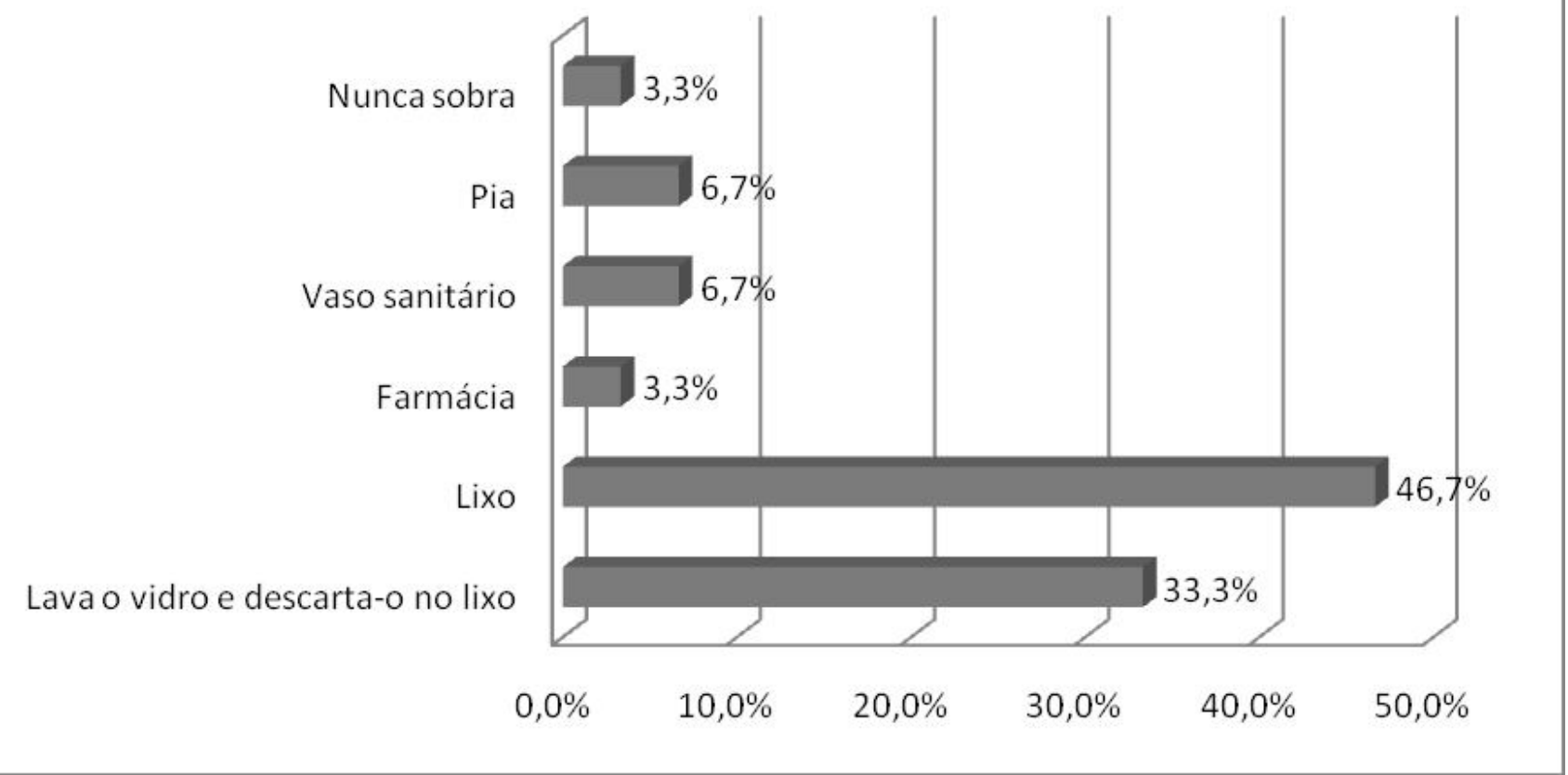

Figura 2 - Local de descarte de medicamentos relatados pelos entrevistados.

Segundo a RDC n. ${ }^{\circ}$ 306, de 7 de dezembro de 2004 (BRASIL, 2004), são enquadrados na classificação B2 todos os resíduos dos medicamentos ou dos insumos farmacêuticos quando vencidos, contaminados, apreendidos para descarte, parcialmente utilizados e demais medicamentos impróprios para consumo, que, em função de seu princípio ativo e forma farmacêutica, não oferecem risco. Incluem-se nesse grupo todos os medicamentos não classificados no Grupo B1 pela mesma resolução e os antibacterianos e hormônios para uso tópico, quando descartados individualmente pelo usuário domiciliar. Portanto, o paracetamol, medicamento analisado por este trabalho, inclui-se no grupo B2.

A mesma resolução ainda estabelece como deve ser realizado o descarte desses grupos de medicamentos. Os do Grupo B1 devem ser encaminhados ao estabelecimento de saúde de referência (farmácia ou local responsável pela coleta, como Vigilância Sanitária, Postos de Saúde, Prefeituras, etc.). As embalagens secundárias não contaminadas deverão ser descaracterizadas e acondicionadas como Resíduo Sólido Urbano, podendo ser encaminhadas para processo de reciclagem. Os locais responsáveis pela coleta deverão encaminhar os resíduos do Grupo B1 ao Aterro Sanitário Industrial para Resíduos Perigosos - Classe I ou serem submetidos a tratamentos de acordo com as orientações do órgão local de meio ambiente, em instalações licenciadas para esse fim. Em se tratando dos resíduos do Grupo B2, estes poderão ser descartados em esgoto sanitário com sistema de tratamento. As embalagens desses produtos deverão ser acondicionadas como resíduo sólido urbano.

Por meio do questionário aplicado neste trabalho, verificou-se que a maior porcentagem citada $(46,7 \%)$ é o descarte de qualquer medicamento (tanto Grupo B1 como B2) diretamente no lixo doméstico. Isso mostra a situação problemática que ainda se observa no Brasil, pois a prática pode trazer prejuízos futuros 
de saúde pública, uma vez que, lamentavelmente, ainda existem pessoas que sobrevivem de restos dos "lixões" da cidade, as quais podem entrar em contato com esses medicamentos e fazer uso inadequado desses produtos, oferecendo riscos à sua saúde (VETTORAZZI; VENAZZI, 2008).

Observou-se, também, que a segunda forma de descarte mais citada foi lavar o vidro e descartá-lo no lixo $(33,3 \%)$, seguida por descartar o medicamento diretamente na pia ou no vaso sanitário, cada um com $6,7 \%$. Somando-se as porcentagens que descartam qualquer medicamento diretamente no esgoto, chega-se a mesma porcentagem descartada no lixo, ou seja, 46,7\%. Isso implica que não são todos os medicamentos que podem ser descartados dessa forma. Como verificado na Resolução RDC n. ${ }^{\circ}$ 306, de 7 de dezembro de 2004 (BRASIL, 2004), resíduos de medicamentos incluídos no Grupo B1 devem ser encaminhados a locais responsáveis pela coleta, como a Vigilância Sanitária local, por exemplo.

Segundo Vetorazzi \& Venazzi (2008), seria importante pensar não apenas na produção e fabricação de medicamentos, mas na necessidade de analisar o impacto que estes geram ao longo de seu ciclo de vida, ou seja, da produção ao descarte. Dessa forma, poderia se avaliar quanto desses resíduos podem ser reutilizados pelos próprios fabricantes, fazendo com que os dejetos não sejam jogados indevidamente junto com o lixo que deve passar para a compostagem. O presente trabalho ainda procura reforçar que todos os setores envolvidos (indústrias, distribuidores e farmácias) devem ter responsabilidade pelo ciclo de vida integral do produto, desde os cuidados para não poluir o ambiente durante a produção, como também a destinação dos resíduos após consumo. Assim, haveria uma cadeia de logística inversa, na qual as farmácias e distribuidoras trabalhariam como receptoras dos medicamentos vencidos entregues pelos consumidores e dariam destino adequado aos mesmos.

Algo semelhante já ocorre no Paraná, que, por meio da Lei Estadual n. ${ }^{\circ} 13.039$, de 11 de janeiro de 2001 (BRASIL, 2001), as farmácias e distribuidores devem receber os medicamentos vencidos levados pelos consumidores e darem destinação adequada aos mesmos, sem a possibilidade jurídica de negar o recebimento.

A grande maioria dos entrevistados relatou utilizar o medicamento contendo paracetamol por aconselhamento médico (90\%) e afirmou ler a bula $(93,3 \%)$. Quando questionados quanto à posologia do medicamento, $46,7 \%$ o utilizam para dor ou febre, $26,7 \%$ só para dor e a mesma porcentagem só para febre (Figura 3). 


\section{Quando administram o medicamento}

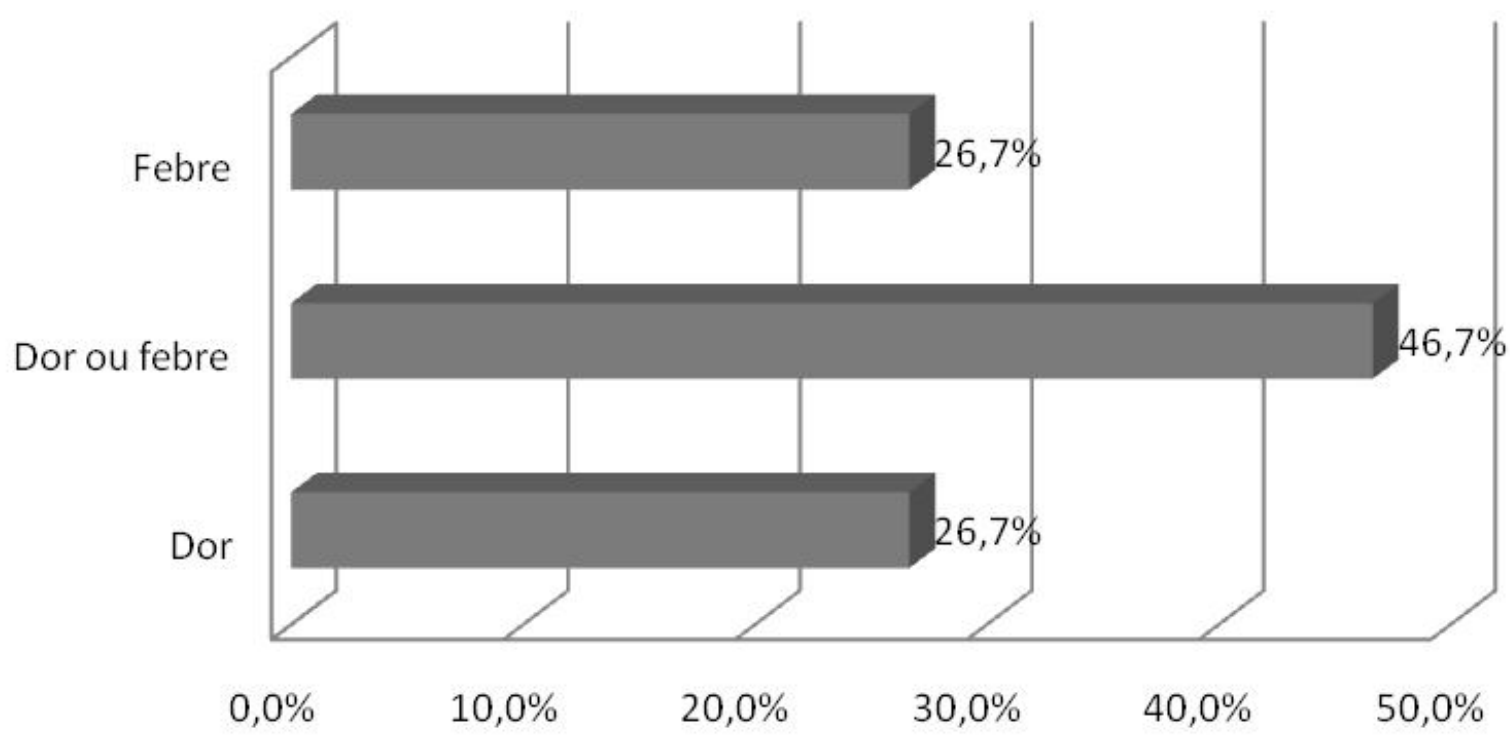

Figura 3 - Sintomas relatados pelos entrevistados para a utilização de paracetamol.

Dentre os entrevistados, $90 \%$ afirmaram utilizar o paracetamol por aconselhamento médico, 93,3\% afirma ler a bula, 86,7\% afirmaram comprar medicamentos apenas com prescrição médica e todos os entrevistados utilizam o mesmo para os sintomas corretos (dor e/ou febre). Um dado interessante observado é que 43,3\% dos entrevistados não conhecem a profissão farmacêutica e, embora a maioria conheça os medicamentos genéricos, $13,3 \%$ relatam o desconhecimento.

A prescrição errônea do paracetamol implica um grave problema, pois se trata de um medicamento com alto potencial hepatotóxico, se ingerido em altas doses ou em associação com algumas substâncias, tais como o álcool, o fenobarbital e a fenitoína (GENNARO, 2004). Com isso, observa-se a importância do acompanhamento, pelo farmacêutico, da terapêutica prescrita, para que a ocorrência de erros de prescrição seja a menor possível e que, quando esta surgir, possa ser resolvida imediatamente, além da correta orientação e informação aos usuários de medicamentos quanto ao armazenamento e conservação da estabilidade dos referidos produtos.

\section{Conclusão}

Com base nos resultados obtidos na análise microbiológica dos medicamentos contendo paracetamol, pode-se concluir que os parabenos (metilparabeno e propilparabeno) e o benzoato de sódio, conservantes utilizados na maioria das formulações analisadas, foram eficientes nas condições experimentais.

Em relação ao questionário aplicado, verificou-se a carência de informação e orientação quanto ao correto armazenamento e descarte, visto que grande parte dos entrevistados não conhece a profissão farmacêutica e descarta os medicamentos de forma errada.

Nesse contexto, destaca-se a necessidade de estímulo aos profissionais recém-formados, de modo a ultrapassar as barreiras para a realização de programas de informação e orientação quanto ao uso 
correto de medicamentos, principalmente seu armazenamento nas residências, a fim de minimizar o risco de contaminação microbiológica dos mesmos, durante o período de validade.

\section{REFERÊNCIAS}

ANDREI, C.C. FERREIRA, D.T.; FACCIONE, $M$. Da química medicinal à química combinatória e modelagem molecular: um curso prático. 2. ed. Barueri: Manole; 2003. p.61-62.

CHANDRASEKHARAN, N.V.; HU, D.; ROOS, K.L.T.; EVANSON, N.K.; TOMSIK, J.; ELTON, T.S.; MMONS, D.L. COX-3, a cyclooxigenase-1 variant inhibited by acetaminophen and other analgesic/antipyretic drugs: cloning, structure, and expression. Proceedings of the National Academy of Sciences (PNAS), v.99, n.21, p.13926-13931, 2002.

BRASIL. Resolução RDC n. ${ }^{\circ} 306$ de 07 de dezembro de 2004. Dispõe sobre o regulamento técnico para o gerenciamento de resíduos de serviços de saúde. Diário Oficial da União, 10 dez 2004.

BRASIL. Resolução RDC n. ${ }^{\circ} 357$ de 20 de abril de 2001. Aprova o regulamento técnico das Boas Práticas de Farmácia. Diário Oficial da União, 27 abr 2001.

BRASIL. Leis, decretos, etc. Lei Estadual n. ${ }^{\circ}$ 13.039 de 11 de janeiro de 2001. Dispõe que é de responsabilidade das indústrias farmacêuticas e das empresas de distribuição de medicamentos, dar destinação adequada a medicamentos com prazos de validade vencidos e adota outras providências. Departamento de Imprensa Oficial do Estado do Paraná, 24 jan 2001.

DE LA ROSA, M.C.; MEDINA, M.R.; VIVAR, C. Microbiological quality of pharmaceutical raw materials. Pharm Acta Helvetiae, v.70, n.3, p.227-232, 1995.

FARMACOPEIA BRASILEIRA. 4. ed. São Paulo: Atheneu; 1988. p.5.1.6-5.1.7.

FERREIRA, A.O. Guia prático da farmácia magistral. 2. ed. Juiz de Fora: Pharmabooks; 2002. p.480-485.

FERREIRA, R. Atenção farmacêutica em homeopatia: casos clínicos. Cult Homeop, São Paulo, v.19, p.34-35, 2007.

FREITAS, E.L.; OLIVEIRA, D.R.; PERINI, E. Atenção farmacêutica-teoria e prática : um diálogo possível Acta Farm Bonaerense, Buenos Aires, v.25, n.3, p.447-453, 2006.

GENNARO, A.R. Remington: a ciência e a prática da farmácia. 20. ed. Rio de Janeiro: Guanabara Koogan; 2004. p.1025-1027, 1513.

HEPLER, C.D.; STRAND, L.M. Oportunidades y responsabilidades de la Atención Farmacéutica. Pharm Care, v.1, n.1, p.35-47, 1999.

KATZUNG, B.G. Farmacologia básica e clínica. 6. ed. Rio de Janeiro: Guanabara Koogan; 1998. 420p.

LIMA, G.B. ; ARAUJO, E.J.F. ; SOUSA, K.M.H. ; BENVIDO, R.F. ; SILVA, W.C.S. ; CORREA JR, R.A.C. ; NUNES, L.C.C. Avaliação da utilização de medicamentos armazenados em domicílios por uma população atendida pelo PSF. Rev Bras Farm, Rio de Janeiro, v.89, n.2, p.146-149, 2008.

LUNARDI, D. ; ZART, D. ; FASOLIN, T. ; GONÇALVES, C.B.T. Atenção farmacêutica para pacientes em uso de capecitabina. Rev Bras Farm, Rio de Janeiro, v.90, n.3, p.250-257, 2009.

LYRA JUNIOR, D. ; AMARAL, R.T. ; ABRIATA, 
J.P. ; PELA, I.R. Satisfacción como resultado de um programa de atención farmacéutica para pacientes ancianos en Ribeirão Preto-São Paulo (Brasil).

Seguimiento Farmacoterapéutico, v.3, n.1, p.3042, 2005.

OLIVEIRA, A.B. ; OYAKAWA, C.N. ; MIGUEL, M.D. ; ZANIN, S.M.W. ; MONTRUCCHIO, D.P. Obstáculos da atenção farmacêutica no Brasil. Braz J Pharm Sci, São Paulo, v.41, n.4, p.409-413, 2005.

OLIVEIRA, A.O.T. ; PEDROSO, C.F. ; MIGUEL, M.D. ; MONTRUCCHIO, D.P. ; ZANIN, S.M.W.; DORNELES, D. Atenção farmacêutica na antibioticoterapia. Visão Acadêmica, Goiânia, v.5, n.1, p.7-14, 2004.

PEREIRA, L.R.L.; FREITAS, O. A evolução da Atenção Farmacêutica e a perspectiva para o Brasil. Braz J Pharm Sci, São Paulo, v.44, n.4, p.601612, 2008.

PINTO, T.J.A.; KANEKO, T.M.; OHARA, M.T. Controle biológico de qualidade de produtos farmacêuticos, correlatos e cosméticos. 2. ed. São Paulo: Atheneu; 2003. p.81-103.

PLACIDO, V.B.; FERNANDES, L.P.S.; GUARIDO, C.F. Contribuição da atenção farmacêutica para pacientes portadores de diabetes atendidos no ambulatório de endocrinologia da Unimar. Rev Bras Farm, Rio de Janeiro, v.90, n.3, p.258-263, 2009.

PRETTI, A.P.; ULIANA, M.P.; COLE, E.R. Uma proposta de atenção farmacêutica em homeopatia. Braz Homeopathic J, São Paulo, v.11910, p.59-60, 2009.

SCHENKEL, E.P.; FERNANDEZ, L.C.; MENGUE, S.S. Como são armazenados os medicamentos nos domicílios? Acta Farm Bonaerense, Buenos Aires, v.24, n.2, p.266-270, 2005.

SERAFIM, E.O.P.; DEL VECCHIO, A.; GOMES, J.; MIRANDA, A.; MORENO, A.H.; LOFFREDO, L.M.C.; SALGADO, H.R.N.; CHUNG, M.C. Qualidade dos medicamentos contendo dipirona encontrados nas residências de Araraquara e sua relação com a atenção farmacêutica. Braz J Pharm Sci, São Paulo, v.43, n.10, p.127-135, 2007.

SOUZA, V.V.; BERTONCIN, A.L.F. Atenção farmacêutica para pacientes hipertensos : nova metodologia e a importância dessa prática no acompanhamento domiciliar. Rev Bras Prom Saúde, Fortaleza, v.21, n.30, p.224-230, 2008.

VETTORAZZI, K.M.; VENAZZI, K.F. Responsabilidade socioambiental dos produtores de medicamentos e farmácias sobre os resíduos sólidos de sáude: a logística reversa como possibilidade de coleta e correta destinação. In : FAE Centro Universitário. III Seminário Sobre

Sustentabilidade da FAE; 2008.

\section{ZAVALETA-BUSTOS, M.; CASTRO-}

PASTRANA, L.I.; REYES-HERNANDEZ, I.; LOPEZ-LUNA, M.A.; BERMUDEZ-CAMPS, I.B. Prescription errors in a primary care university unit: urgency of pharmaceutical care in Mexico. Braz J Pharm Sci, São Paulo, v.44, n.1, p.115-125, 2008. 